(2) Open Access Full Text Article

\title{
Accuracy of axial length measurements obtained by optical biometry and acoustic biometry in rhegmatogenous retinal detachment: a prospective study
}

This article was published in the following Dove Press journal:

Clinical Ophthalmology

\section{Pear Pongsachareonnont Sagol Tangjanyatam}

Vitreoretinal Research Unit, Department of Ophthalmology, Faculty of Medicine, Chulalongkorn University and King Chulalongkorn Memorial Hospital, Thai Red Cross Society, Bangkok, Thailand
Correspondence: Pear Pongsachareonnont Department of Ophthalmology, Faculty of Medicine, Chulalongkorn University and King chulalongkorn Memorial Hospital, I873 Rama IV Road, Pathumwan, Bangkok 10330, Thailand Tel +6622564142 ext 0 Fax +6622873722 Email pear.p@chulahospital.org
Purpose: We compared the accuracy of axial length (AL) measurement obtained by optical biometry with that obtained by acoustic biometry in eyes with rhegmatogenous retinal detachment (RRD).

Patients and methods: This prospective descriptive analytic study measured the AL of eyes with RRD preoperatively and 3 months postoperatively using optical biometry (intraocular lens [IOL] master group) and acoustic biometry (immersion A-scan group). Preoperative and postoperative measurements were compared by paired $t$-test. The agreement between preoperative and postoperative measurements was analyzed using a Bland-Altman plot. Subgroup analysis of macular involvement status was performed.

Results: Twenty-seven eyes were analyzed in this study. The mean AL in the IOL master group was $23.58 \pm 0.97 \mathrm{~mm}$ preoperatively and $24.17 \pm 1.16 \mathrm{~mm}$ postoperatively; the mean difference was $-0.59 \pm 0.90 \mathrm{~mm}(P=0.007)$. The mean $\mathrm{AL}$ in the immersion A-scan group was $24.29 \pm 1.59 \mathrm{~mm}$ preoperatively and $24.27 \pm 1.69 \mathrm{~mm}$ postoperatively; the mean difference was $0.02 \pm 0.48 \mathrm{~mm}(P=0.827)$. Bland-Altman analysis revealed disagreement between preoperative and postoperative AL measurements in both techniques. In subgroup analysis of macula with RRD, there were significant differences between preoperative and postoperative AL measurements in the IOL master group $(P=0.014)$.

Conclusion: Significant underestimation of AL measurement was observed when using the IOL master in eyes with RRD with macular involvement, which could affect IOL power selection.

Keywords: IOL biometry, phacoemulsification, phacovitrectomy, cataract surgery biometry

\section{Introduction}

Development of cataracts after vitrectomy is common and subsequent cataract surgery is often required. ${ }^{1}$ Pars plana vitrectomy (PPV) for the treatment of rhegmatogenous retinal detachment (RRD) is technically more difficult in phakic eyes. Moreover, lens status may affect the success rate of surgical repair. ${ }^{2}$ Lens removal in conjunction with PPV for RRD was shown to reduce the need for a second operation for cataract surgery $^{3}$ and to improve surgery outcomes. ${ }^{4,5}$ Primary and secondary intraocular lens (IOL) implantation can be considered when combined phacoemulsification and PPV is the treatment of choice. The major advantage of secondary IOL implantation is the improved accuracy of IOL power calculation, because all biometric parameters are measured under a stable status after the surgery. However, with this approach, the 
patient endures an aphakic status for weeks and requires at least two operations to improve vision as best as possible. Although combined phacoemulsification and PPV with primary IOL implantation has consequently become a common procedure, ${ }^{4-6}$ IOL power calculation is challenging for the combined operation of retinal detachment surgery with IOL implantation.

Axial length (AL) is the main variable for IOL power calculation in all formulas and is measured using preoperative optical biometry or acoustic biometry. Using optical biometry, AL measurement is obtained by noncontact partial coherence laser interferometry that is based on the signal of the retinal pigment epithelium (RPE). In contrast, when using acoustic biometry, AL measurement is obtained by A-scan ultrasound based on the signal of the internal limiting membrane. There are two techniques (the applanation and immersion techniques) for A-scan biometry. The immersion technique is standard for AL measurement because corneal compression of the applanation technique can interfere with the measurement. ${ }^{7}$ Compared to acoustic biometry, optical biometry is reportedly more accurate in cataract eyes without other pathologies. ${ }^{8,9}$ Given the pathophysiology of the disease, the AL should be shorter in eyes with retinal detachment. This means that AL is often underestimated by the waveform of the detached retina and, accordingly, IOL power is overestimated. A preoperative error in AL measurement of $0.3 \mathrm{~mm}$ results in a $0.75 \mathrm{D}$ difference in IOL power calculation, which is clinically significant. ${ }^{10}$

The purpose of this study was to compare the accuracy of AL measurement obtained by partial coherence laser interferometry with that obtained by A-scan immersion biometry in patients with RRD.

\section{Patients and methods}

Patients with RRD from the outpatient department of King Chulalongkorn Memorial Hospital (Bangkok, Thailand), who were scheduled for treatment with PPV or pneumatic retinopexy, and provided informed consent, were enrolled in this study. We excluded RRD patients who had been treated with scleral buckling procedure (SBP); had received a previous silicon oil (SO) injection; had undergone previous scleral surgery; had a history of full-thickness laceration of the globe; or had suffered from other ocular problems that might influence the AL measurement, such as a corneal scar. This study took place from April 1, 2015, to June 30, 2016. The study was approved by the Institutional Review Board (IRB) of the Faculty of Medicine of Chulalongkorn University (IRB approval No 594/57). The clinical trial was registered with the Thai Clinical Trial Registry (TCTR20150308001).
The protocol conforms to the provisions outlined by the Declaration of Helsinki.

AL measurement of 40 RRD eyes was performed using the ZEISS IOL Master $500^{\circledR}$ (IOL master group; Oberkochen, Germany) and Alcon OcuScan ${ }^{\circledR}$ (immersion A-scan group, Fribourg, Switzerland) within 2 weeks before retinal surgery and at 3 months after surgery when the retina was documented as being attached, as indicated by observation by a retina specialist using a slit-lamp and fundus ophthalmoscope. The A-scan measurement was automated selection by machine and manual checked by a well-trained technician. Ten measurements with result $<0.1 \mathrm{~mm}$ between each measurement were selected to calculate the final AL. Retinal detachment with macula-on was determined by clinical examination combined with absence of subretinal fluid in the fovea on optical coherence tomography (Spectralis ${ }^{\circledR}$, Heidelberg Engineering, Germany). In redetachment RRD, AL evaluation was performed at 3 months after the last operation of successful retinal detachment repair. The mode of measurement was chosen as phakia, pseudophakia, or aphakia depending on the current lens status of the patient in both optical and acoustic biometry.

There were three operators who measured AL in this study. The interobserver correlation was evaluated by intraclass correlation in 10 eyes before starting the study. All three operators had $>5$ years of experience in measuring AL with both modalities and were masked from preoperative data when measuring postoperative AL.

The normality of data was evaluated by a Q-Q plot. The means of the preoperative and postoperative AL measurements were compared in each IOL master group and immersion A-scan group using a paired $t$-test. The agreement between the two groups for preoperative and postoperative AL measurements was analyzed using a Bland-Altman plot.

Statistical analyses were performed using SPSS 23.0 (SPSS Inc., Chicago, IL, USA). The statistical significance was set at $P<0.05$.

Power analysis was performed using Medcalc ${ }^{\circledR}$ (Ostend, Belgium) with alpha of 0.05 and beta of 0.10 . The SD was set at $0.30 \mathrm{~mm}$, which was estimated from a previous study. ${ }^{11}$ A difference of means of $0.30 \mathrm{~mm}$ was used as it correlates to a clinically significant $0.75 \mathrm{D}$ error in IOL power calculation. The estimated sample size was 22 eyes in each group.

\section{Results}

Forty eyes with retinal detachment were enrolled in this study. Among these, 13 were excluded because of eight subsequent SBP and five subsequent SO injections. Therefore, 27 eyes of 27 patients were analyzed, with the age of the 
patients ranging from 20 to 76 years. The patient's clinical characteristics are summarized in Table 1.

For AL measurement, the interobserver correlation between three operators was evaluated by intraclass correlation in 10 eyes (five RRD eyes and five normal eyes) before the study began. Interobserver agreement was indicated by an intraclass correlation coefficient of 0.993 . The normality of data was evaluated using a Q-Q plot, which suggested that the data were sufficiently normally distributed.

The mean AL in the IOL master group was $23.58 \pm 0.97 \mathrm{~mm}$ preoperatively and $24.17 \pm 1.16 \mathrm{~mm}$ postoperatively; the mean difference was $-0.59 \pm 0.90 \mathrm{~mm}(95 \% \mathrm{CI},-1.00$ to -0.18 ; $P=0.007)$. The mean AL in the immersion A-scan group was $24.29 \pm 1.59 \mathrm{~mm}$ preoperatively and $24.27 \pm 1.69 \mathrm{~mm}$ postoperatively; the mean difference was $0.02 \pm 0.48 \mathrm{~mm}$ (95\% CI, -0.17 to $0.21 ; P=0.827$ ), as shown in Table 2 . Figures 1 and 2 show that the preoperative or postoperative AL values obtained by IOL master and immersion A-scan were not correlated, as indicated by a Bland-Altman plot. The limit of agreement was set at $0.3 \mathrm{~mm}$, which results in a clinically significant IOL power error of $0.75 \mathrm{D} .^{10}$

Table I Clinical characteristics of 27 patients with rhegmatogenous retinal detachment

\begin{tabular}{|c|c|}
\hline Characteristics & n (\%) \\
\hline Age (years) & $55.3 \pm 15.4^{a}$ \\
\hline Male & $12(44)$ \\
\hline Right eye & $15(56)$ \\
\hline \multicolumn{2}{|l|}{ Lens status } \\
\hline Aphakia & I (4) \\
\hline Phakia & $18(66)$ \\
\hline Pseudophakia & $8(30)$ \\
\hline \multicolumn{2}{|l|}{ Type } \\
\hline Primary & $26(96)$ \\
\hline Recurrent & I (4) \\
\hline \multicolumn{2}{|l|}{ Presentation } \\
\hline Acute $(<6$ weeks) & $26(96)$ \\
\hline Chronic (>6 weeks) & I (4) \\
\hline \multicolumn{2}{|l|}{ Macular status } \\
\hline Macula-on & II (4I) \\
\hline Macula-off & $16(59)$ \\
\hline \multicolumn{2}{|l|}{ Severity } \\
\hline Shallow & $12(44)$ \\
\hline Bullous & $15(56)$ \\
\hline \multicolumn{2}{|l|}{ PVR grade } \\
\hline No PVR & I (4) \\
\hline Grade A & $14(5 \mid)$ \\
\hline Grade B & II (4I) \\
\hline Grade C & I (4) \\
\hline \multicolumn{2}{|l|}{ Operation } \\
\hline PPV & $23(85)$ \\
\hline Pneumatic retinopexy & $4(15)$ \\
\hline \multicolumn{2}{|l|}{ Gas tamponade } \\
\hline $\mathrm{SF}_{6}$ & $3(I I)$ \\
\hline $\mathrm{C}_{3} \mathrm{~F}_{8}$ & $24(89)$ \\
\hline
\end{tabular}

Note: avalues presented as the mean \pm SD.

Abbreviations: PPV, pars plana vitrectomy; PVR, proliferative vitreoretinopathy.
In a subgroup analysis of 11 macula-on eyes, the $\mathrm{AL}$ measurements were not significantly different between preoperative and postoperative measurements $(P=0.25$ in the IOL master group and $P=0.98$ in the immersion A-scan group), as shown in Table 3. The Bland-Altman plot showed good agreement in the A-scan group, as shown in Figure 3. The Bland-Altman plot of the IOL master group (Figure 4) also showed agreement, with the exception of one outlier that could be the result of measurement error.

In subgroup analysis of 16 macula-off eyes, the mean difference between preoperative and postoperative AL was significantly different in the IOL master group $(P=0.014$ in the IOL master group and $P=0.83$ in the immersion A-scan group), as shown in Table 4.

\section{Discussion}

The current methods for AL measurement are partial coherence laser interferometry and ultrasound A-scan biometry, which are based on the signal of the RPE and the internal limiting membrane, respectively. The immersion A-scan is more accurate than the applanation A-scan and is the standard technique for $\mathrm{AL}$ measurement. ${ }^{12}$ The $\mathrm{AL}$ results and IOL biometry obtained by IOL master and immersion A-scan are highly correlated in a positive manner. ${ }^{9,12}$ In retinal detachment surgery, an increase in AL after retinal surgery is significant only after scleral buckle surgery. ${ }^{13,14} \mathrm{~A}$ previous retrospective study showed significant myopic progression after PPV for retinal detachment; however, the refractive change in these studies was affected by cataract progression or keratometric value change. ${ }^{15}$ The postoperative refractive outcome, which shifted toward myopia, was also observed after combining phacoemulsification and PPV for RRD treatment. ${ }^{16}$ AbouShousha et al found a significantly longer AL measurement after PPV in macula-off RRD when obtained by IOL master and A-scan ultrasound. However, SO-filled eyes were included and the applanation technique of A-scan ultrasound biometry was used in this previous study. ${ }^{17}$ Rahman et al ${ }^{18}$ reported retrospective case review of 100 eyes that underwent phacovitrectomy for the treatment of RRD. By using the mean absolute prediction error (MAE), which was calculated based on the predicted refraction and postoperative refraction, optical biometry was shown to be more accurate than ultrasound biometry, with a mean MAE difference of 0.16 . However, the study only used predicted refraction and postoperative refraction and was not designed to compare and evaluate the change of AL measurement after PPV.

This study showed a significant difference between preoperative and postoperative AL measurement in the IOL master group. The mean difference was $-0.59 \pm 0.90 \mathrm{~mm}$, which 
Table 2 Preoperative and postoperative mean AL obtained by IOL master and immersion A-scan ultrasound $(n=27)$

\begin{tabular}{lllllll}
\hline & N (eyes) & \multicolumn{2}{l}{ Mean AL $(\mathbf{m m}) \pm$ SD } & & P-value* & 95\% Cl \\
\cline { 2 - 5 } & & Preoperative & Postoperative & Difference & \\
\hline IOL master & $2 \mathrm{I}^{\mathrm{a}}$ & $23.58 \pm 0.97$ & $24.17 \pm 1.16$ & $-0.59 \pm 0.90$ & 0.007 & -1.00 to -0.18 \\
Immersion A-scan & 27 & $24.29 \pm 1.59$ & $24.27 \pm 1.69$ & $0.02 \pm 0.48$ & 0.827 & -0.17 to 0.21 \\
\hline
\end{tabular}

Notes: asix eyes had error measurement when AL was obtained by $\mathrm{OOL}$ master preoperatively. *Paired $t$-test; $P<0.05$ was assumed to indicate significance. Abbreviations: $\mathrm{AL}$, axial length; IOL, intraocular lens.

resulted in an overestimation of IOL power by $\sim 1.5 \mathrm{D}$, which is clinically significant. Conversely, there was no significant difference between preoperative and postoperative AL measurement obtained by immersion A-scan ultrasound. A small mean difference of $0.02 \pm 0.48 \mathrm{~mm}$ was noted and showed disagreement. Additionally, the Bland-Altman plot showed disagreement within the limit of agreement of $0.3 \mathrm{~mm}$.

The subgroup analysis of this study showed no significant difference between preoperative and postoperative AL measurements in macula-on RRD when measured by both IOL master and A-scan ultrasound, which is clinically acceptable for IOL power calculation. The Bland-Altman analysis also showed agreement in eyes with an attached retina in the macular area, which does not interfere with patient fixation and IOL biometry. The subgroup analysis in macula-off eyes showed that the AL measured by IOL master was significantly shorter preoperatively and exhibited a mean difference of -0.98 , which may significantly overestimate IOL power by $>2.5 \mathrm{D}$. Conversely, A-scan ultrasound AL measurement showed no significant difference between pre- and postoperative AL, with a mean difference of 0.03 . However, the subgroup analysis study size was relatively small; therefore, it may be underpowered to detect a true statistically significant difference.

In eyes with retinal attachment, IOL master provides an accurate AL measurement when compared with A-scan biometry. ${ }^{19}$ Similar results have been found in SO-filled eyes with attached retinas. ${ }^{20}$ The immersion A-scan ultrasound appears to be more accurate than the IOL master when used to measure eyes with retinal detachment. This may be due to the detached retina interfering with light reflectivity, thereby resulting in the interpretation of signals from the detached

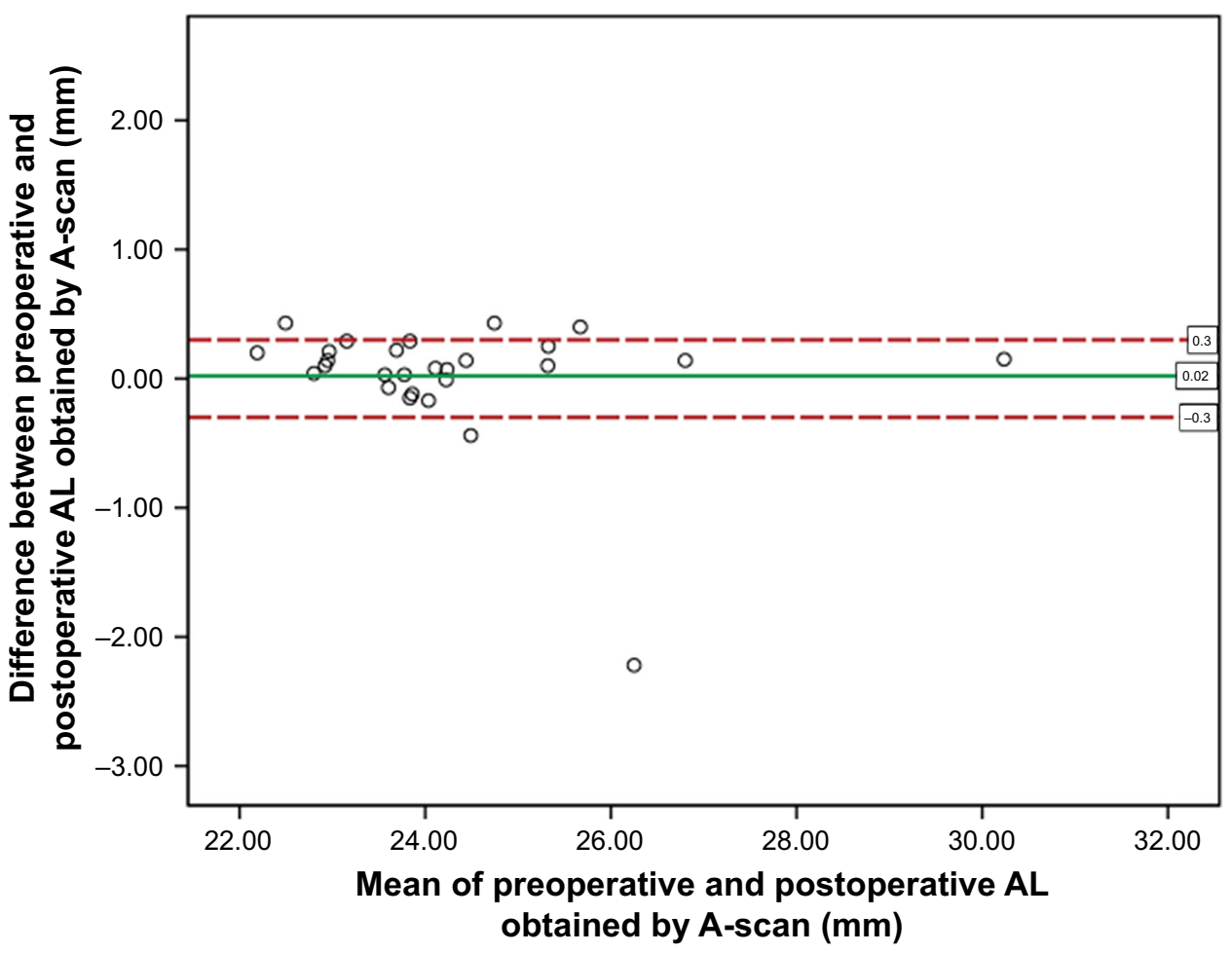

Figure I Bland-Altman plot between preoperative and postoperative axial length obtained by A-scan biometry. Abbreviation: $\mathrm{AL}$, axial length. 


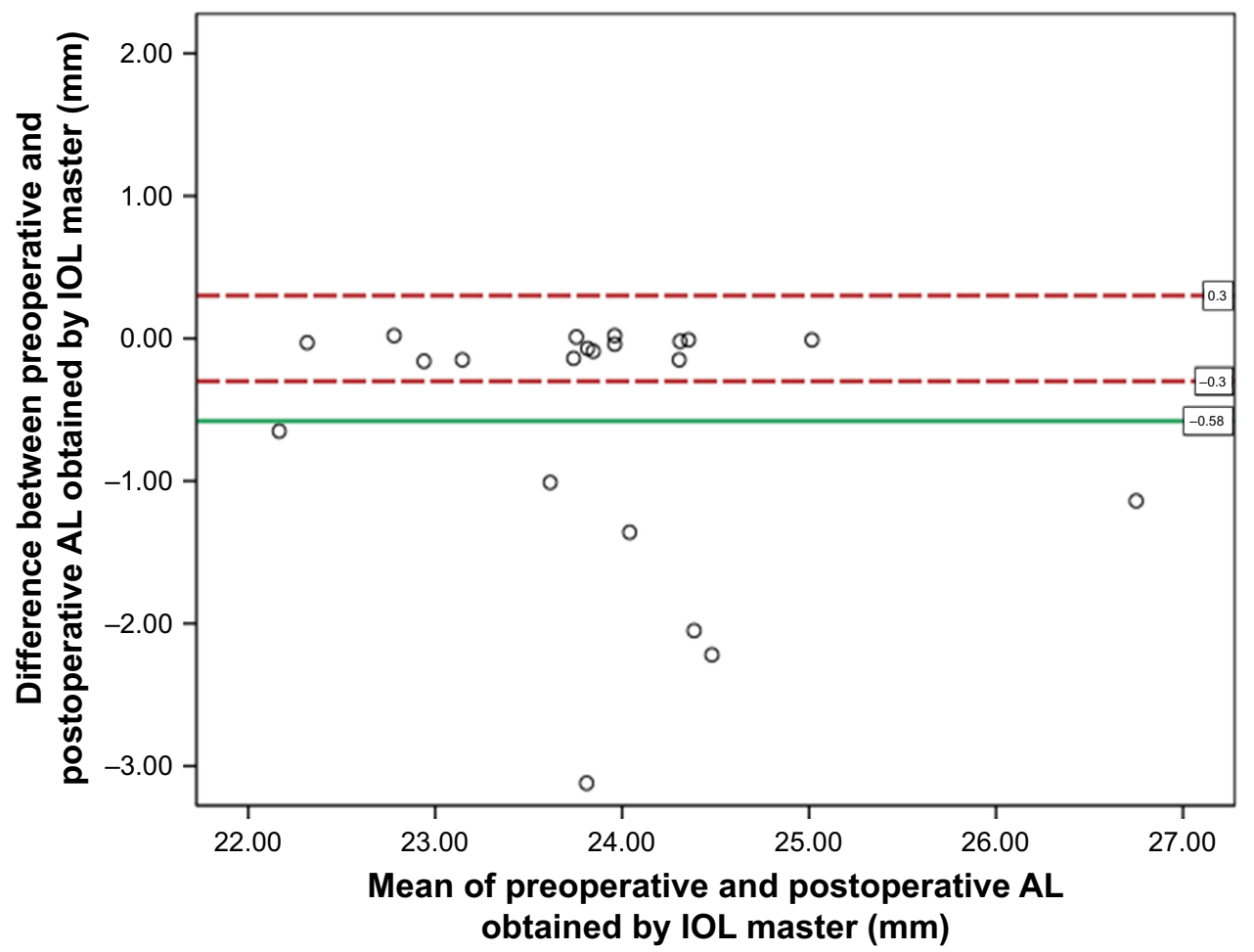

Figure 2 Bland-Altman plot between preoperative and postoperative axial length obtained by optical biometry. Abbreviations: $\mathrm{AL}$, axial length; IOL, intraocular lens.

retina, rather than the RPE, which are obtained during optical biometry. Lege and Haigis reported varied AL measurement results from laser interference biometry (LIB) in cataract surgery with par plana vitrectomy for retinal detachment. In patients with central retinal detachment who cannot fixate, LIB produces a good signal-to-noise ratio from the detached retina, which results in the misinterpretation of AL. ${ }^{21}$ Furthermore, patients with retinal detachment involving the macula may have poor fixation, which interferes with the alignment of the scan. Meanwhile, immersion A-scan ultrasound measures signals from the internal limiting membrane, which could underestimate the true $\mathrm{AL}$ in eyes with retinal detachment. In our study, A-scan produced more accurate AL measurements in macula-off retinal detachment. This may be due to the IOL master measuring $\mathrm{AL}$ in patients who are in an upright position, which results in the detached retina moving away from the RPE. In contrast, eventhough the A-scan biometry measured the signal of retina at the level of the internal limiting membrane, the supine position required to perform immersion A-scan measurements may somehow disperse subretinal fluid away from the macula area, which reduces AL measurement error when compared to postoperative retinal attachment. Moreover, the received A-scan signal chosen by the operator might come from an area of attached retina that displays a better A-scan signal compared to the detached area. This result is similar to that of a previous study that showed an accurate AL measurement of macula-off RRD obtained by an experienced technician using a vector $\mathrm{A} / \mathrm{B}$ scan ultrasound, which allowed for the direct visualization of the attached area being measured. ${ }^{17}$ However, the study was designed to test the agreement of AL measurement between two instruments, which might

Table 3 Preoperative and postoperative mean $\mathrm{AL}$ obtained by $\mathrm{IOL}$ master and immersion A-scan ultrasound of macula-on rhegmatogenous retinal detachment $(n=I I)$

\begin{tabular}{lllllll}
\hline & N (eyes) & \multicolumn{2}{c}{ Mean AL $(\mathbf{m m}) \pm$ SD } & & P-value* & 95\% Cl \\
\cline { 3 - 6 } & & Preoperative & Postoperative & Difference & & \\
\hline IOL master & II & $23.67 \pm 0.64$ & $23.90 \pm 0.81$ & $-0.22 \pm 0.60$ & 0.247 & -0.63 to 0.18 \\
Immersion A-scan & II & $23.779 \pm 0.77 \mathrm{I}$ & $23.778 \pm 0.806$ & $0.001 \pm 0.117$ & 0.980 & -0.78 to 0.08 \\
\hline
\end{tabular}

Notes: *Paired $t$-test; $P<0.05$ was set for significance.

Abbreviations: AL, axial length; IOL, intraocular lens. 


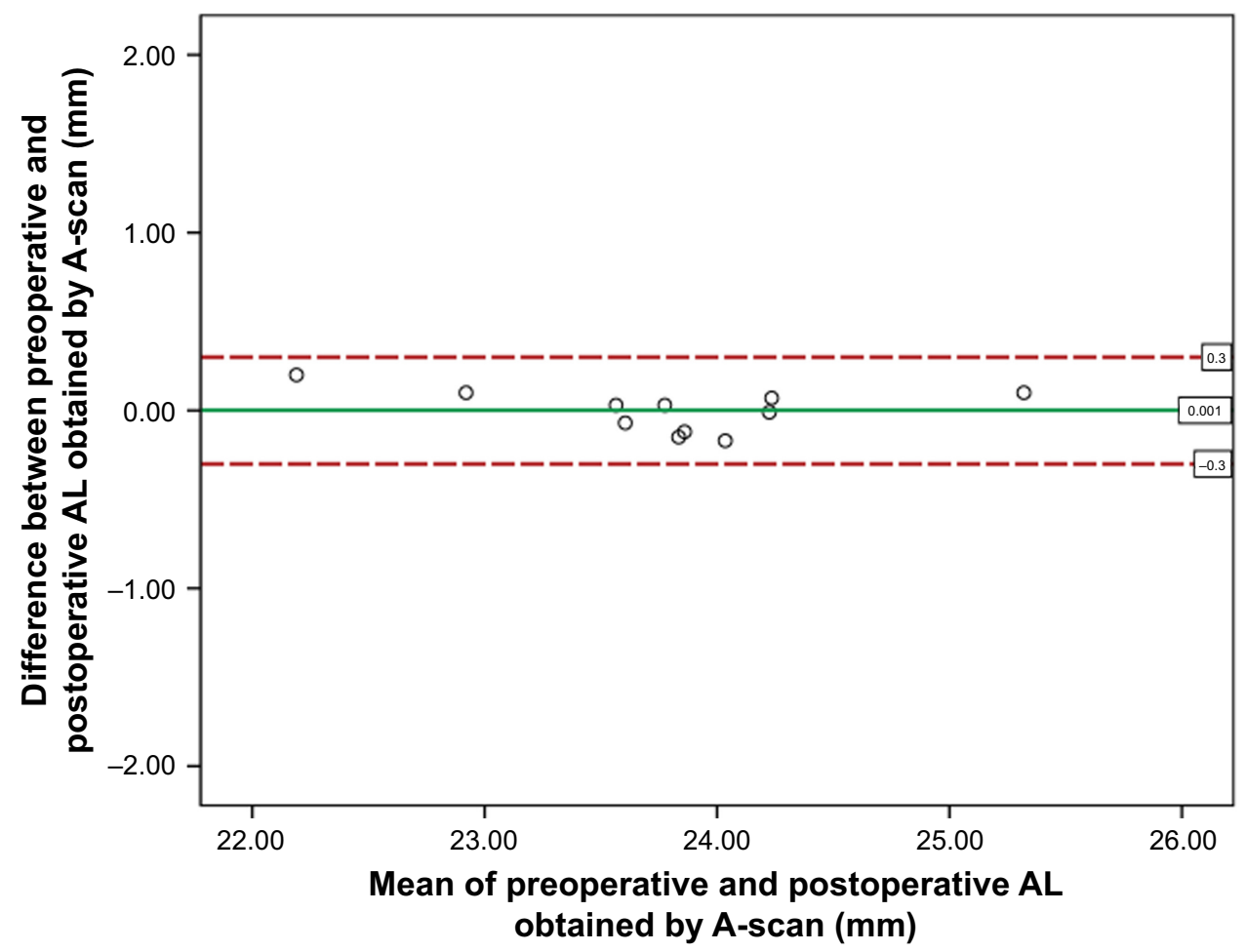

Figure 3 Bland-Altmand plot between preoperative and postoperative axial length obtained by A-scan in the subgroup of macula on rhegmatogenous retinal detachment. Abbreviation: AL, axial length.

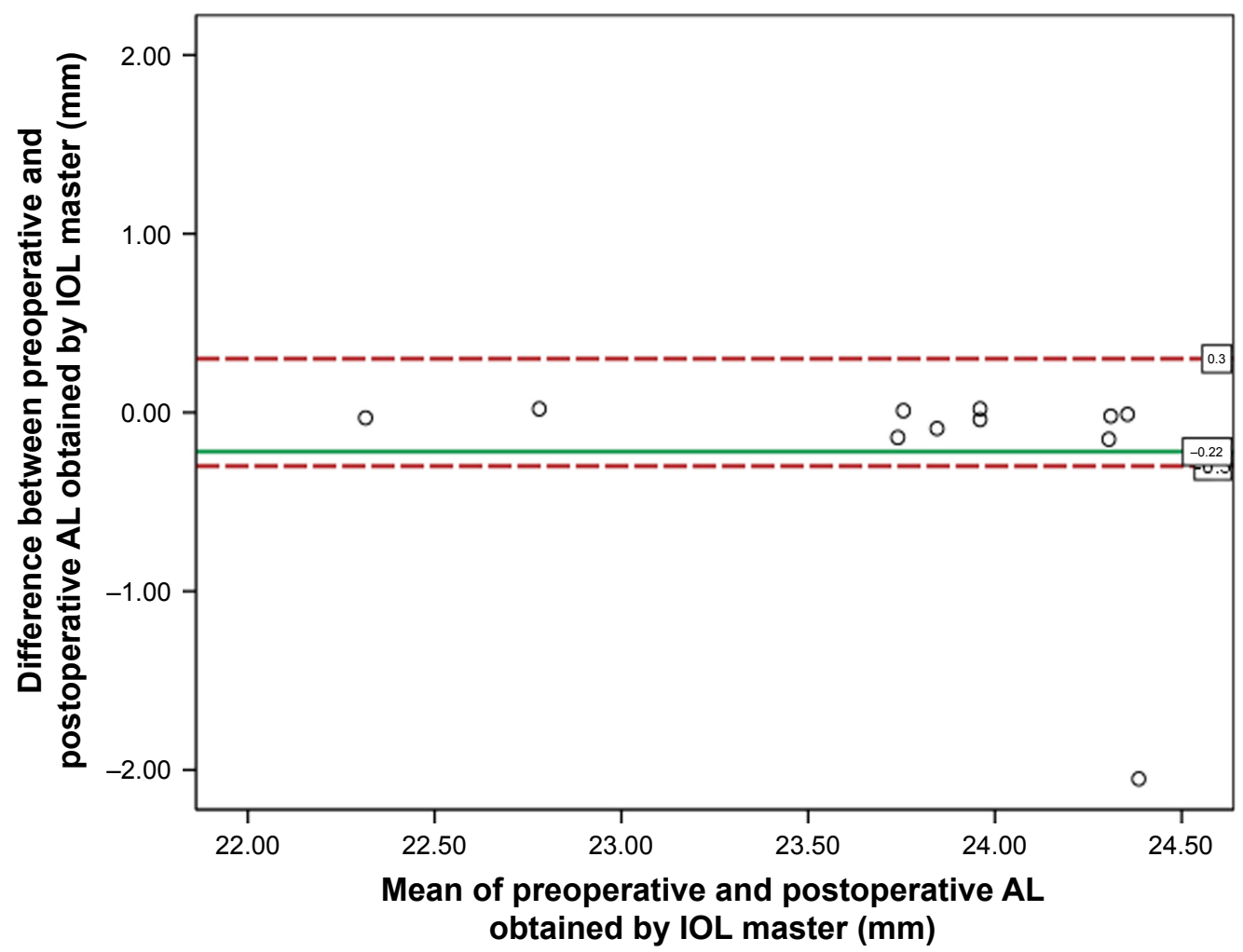

Figure 4 Bland-Altman plot between preoperative and postoperative axial length obtained by optical biometry in the subgroup of macula on rhegmatogenous retinal detachment.

Abbreviations: $\mathrm{AL}$, axial length; IOL, intraocular lens. 
Table 4 Preoperative and postoperative mean AL obtained by IOL master and immersion A-scan ultrasound of 16 patients with macula-off rhegmatogenous retinal detachment

\begin{tabular}{lllllll}
\hline & \multirow{2}{*}{ N (eyes) } & \multicolumn{2}{l}{ Mean AL $(\mathbf{m m}) \pm$ SD } & & P-value* & 95\% Cl \\
\cline { 2 - 5 } & & Preoperative & Postoperative & Difference & \\
\hline IOL master & $10^{\mathrm{a}}$ & $23.48 \pm 1.27$ & $24.47 \pm 1.43$ & $0.98 \pm 1.02$ & 0.014 & -1.72 to -0.25 \\
Immersion A-scan & 16 & $24.63 \pm 1.91$ & $24.60 \pm 2.05$ & $0.03 \pm 0.63$ & 0.83 I & -0.30 to 0.37 \\
\hline
\end{tabular}

Notes: aSix eyes had error measurement when AL was obtained by IOL master preoperatively. *Paired $t$-test; $P<0.05$ was set for significance.

Abbreviations: $A L$, axial length; $I O L$, intraocular lens.

not be the best way to describe accuracy of the biometry measurement.

There were some limitations to this study. First, the subjects were predominantly patients with acute primary RRD who underwent PPV with $\mathrm{C}_{3} \mathrm{~F}_{8}$ injection. This may result in limitations to generalizing our findings. Second, the different positions required of patients during measurement (ie, upright for IOL master measurements and supine for immersion A-scan ultrasound measurement) might interfere with the level of detachment, which can cause a falsely positive retinal signal. In eyes with RRD, the retina could be dynamic and the position of the patient could affect the AL measurement. Third, in this study, the IOL Master 500 was used, which does not have a macular alignment confirmation feature. The latest IOL Master 700 may produce a different result. Fourth, there was no OCT scan at 3 months after operation. The subclinical persistence of subretinal fluid might cause possible bias. Finally, this study has a small sample size that might affect the power of different detection. The subgroup size was relatively small to be sufficiently powerful to detect a difference in subgroup analysis. A larger sample size study should be considered in this special group of patients.

\section{Conclusion}

This study offers evidence of significant underestimation of AL measurement obtained by IOL master in eyes with retinal detachment involving the macula, which significantly affects IOL power selection. In cases without macular involvement, the pre- and postoperative AL measurements obtained by the IOL master and immersion A-scan ultrasound were not significantly different and did not significantly affect IOL power calculation. In eyes with macular involvement, the immersion A-scan ultrasound appears to be more accurate. However, the AL should be obtained by both modalities in cases of retinal detachment and the method used to determine IOL power selection should be carefully considered if there is no correlation of AL results from both techniques.

\section{Acknowledgments}

We thank Cameron Paul Hurst, PhD, for statistical consultancy. This study was funded by Ratchadapisek Sompoch Endowment Fund, Chulalongkorn University.

\section{Author contributions}

Dr Pear Pongaschareonnont and Dr Sagol Tangjanyatam had full access to all of the study data and took responsibility for the integrity of the data and the accuracy of the data analysis. Both authors contributed toward data analysis, drafting and revising the paper and agree to be accountable for all aspects of the work.

\section{Disclosure}

The authors report no conflicts of interest in this work.

\section{References}

1. West S. Progression of nuclear sclerosis and long-term visual results of vitrectomy with transforming growth factor beta-2 for macular holes. Am J Ophthalmol. 1995;119:819.

2. Caiado RR, Magalhaes O Jr, Badaro E, et al. Effect of lens status in the surgical success of 23-gauge primary vitrectomy for the management of rhegmatogenous retinal detachment: the Pan American Collaborative Retina Study (PACORES) group results. Retina. 2015;35:326-333.

3. Lahey JM, Francis RR, Kearney JJ. Combining phacoemulsification with pars plana vitrectomy in patients with proliferative diabetic retinopathy: a series of 223 cases. Ophthalmology. 2003;110:1335-1339.

4. Savastano A, Savastano MC, Barca F, Petrarchini F, Mariotti C, Rizzo S. Combining cataract surgery with 25 -gauge high-speed pars plana vitrectomy: results from a retrospective study. Ophthalmology. 2014;121:299-304.

5. Koenig SB, Mieler WF, Han DP, Abrams GW. Combined phacoemulsification, pars plana vitrectomy, and posterior chamber intraocular lens insertion. Arch Ophthalmol. 1992;110:1101-1104.

6. Chung TY, Chung H, Lee JH. Combined surgery and sequential surgery comprising phacoemulsification, pars plana vitrectomy, and intraocular lens implantation: comparison of clinical outcomes. J Cataract Refract Surg. 2002;28:2001-2005.

7. Schelenz J, Kammann J. Comparison of contact and immersion techniques for axial length measurement and implant power calculation. J Cataract Refract Surg. 1989;15:425-428.

8. Drexler W, Findl O, Menapace R, et al. Partial coherence interferometry: a novel approach to biometry in cataract surgery. Am J Ophthalmol. 1998;126:524-534.

9. Rajan MS, Keilhorn I, Bell JA. Partial coherence laser interferometry vs conventional ultrasound biometry in intraocular lens power calculations. Eye (Lond). 2002;16:552-556. 
10. Olsen T. Calculation of intraocular lens power: a review. Acta Ophthalmol Scand. 2007;85:472-485.

11. Jeoung JW, Chung H, Yu HG. Factors influencing refractive outcomes after combined phacoemulsification and pars plana vitrectomy: results of a prospective study. J Cataract Refract Surg. 2007;33:108-114.

12. Packer M, Fine IH, Hoffman RS, Coffman PG, Brown LK. Immersion A-scan compared with partial coherence interferometry: outcomes analysis. J Cataract Refract Surg. 2002;28:239-242.

13. Huang C, Zhang T, Liu J, Ji Q, Tan R. Changes in axial length, central cornea thickness, and anterior chamber depth after rhegmatogenous retinal detachment repair. BMC Ophthalmol. 2016;16:121.

14. Vukojevic N, Sikic J, Curkovic T, et al. Axial eye length after retinal detachment surgery. Coll Antropol. 2005;29(Suppl 1):25-27.

15. Okamoto Y, Okamoto F, Hiraoka T, Oshika T. Refractive changes after lens-sparing vitrectomy for rhegmatogenous retinal detachment. Am J Ophthalmol. 2014;158:544-549.e541.

16. Cho KH, Park IW, Kwon SI. Changes in postoperative refractive outcomes following combined phacoemulsification and pars plana vitrectomy for rhegmatogenous retinal detachment. Am J Ophthalmol. 2014;158: 251-256.e252.
17. Abou-Shousha M, Helaly HA, Osman IM. The accuracy of axial length measurements in cases of macula-off retinal detachment. Can $J$ Ophthalmol. 2016;51:108-112.

18. Rahman R, Bong CX, Stephenson J. Accuracy of intraocular lens power estimation in eyes having phacovitrectomy for rhegmatogenous retinal detachment. Retina. 2014;34:1415-1420.

19. Rose LT, Moshegov CN. Comparison of the Zeiss IOLMaster and applanation A-scan ultrasound: biometry for intraocular lens calculation. Clin Exp Ophthalmol. 2003;31:121-124.

20. Kunavisarut $P$, Poopattanakul $P$, Intarated $C$, Pathanapitoon K. Accuracy and reliability of IOL master and A-scan immersion biometry in silicone oil-filled eyes. Eye (Lond). 2012;26:1344-1348.

21. Lege B, Haigis W. Laser interference biometry versus ultrasound biometry in certain clinical conditions. Graefes Arch Clin Exp Ophthalmol. 2004;242:8-12.
Clinical Ophthalmology

\section{Publish your work in this journal}

Clinical Ophthalmology is an international, peer-reviewed journal covering all subspecialties within ophthalmology. Key topics include: Optometry; Visual science; Pharmacology and drug therapy in eye diseases; Basic Sciences; Primary and Secondary eye care; Patient Safety and Quality of Care Improvements. This journal is indexed on

Submit your manuscript here: http://www.dovepress.com/clinical-ophthalmology-journal

\section{Dovepress}

PubMed Central and CAS, and is the official journal of The Society of Clinical Ophthalmology (SCO). The manuscript management system is completely online and includes a very quick and fair peer-review system, which is all easy to use. Visit http://www.dovepress.com/ testimonials.php to read real quotes from published authors. 